doi: $10.17746 / 2658-6193.2021 .27 .0228-0232$

УДК 902/904

\author{
А.Г. Рыбалко $₫$, А.В. Кандыба \\ Институт археологии и этнографии СО РАН \\ Новосибирск, Россия \\ E-mail: rybalko@archaeology.nsc.ru
}

\title{
Исследования раннепалеолитических комплексов стоянки Дарвагчай-Залив-4 в 2021 году
}

В статье представлены новейшие результаты, полученные в ходе исследований многослойной стоянки Дарвагчай-Залив-4 (Юго-Восточный Дагестан). В проиессе раскопок были обнаружены дополнительные археологические материаль, подтверждаюшие наличие на стоянке двух раннепалеолитических комплексов артефактов, точные хронологические рамки которых были установлены по результатам анализа малакофауны, палеомагнитных исследований и абсолютного датирования методом OSL. Каменная индустрия первого комплекса, обнаруженная в слое 3 (галечно-гравийные отложения), относятся к финальному ашелю. Ведущую роль в осадконакоплении здесь играли элювиально-делювиальные и пролювиальные процессы. Возраст культуросодержащего горизонта установлен в интервале 250-220 тыс. л.н. (MIS 7). Коллекция каменных изделий, раскопанная в слое 5 (морские галечники и пески), относится к позднему ашелю и является свидетельством самого раннего появления древнего человека на рассматриваемой территории (380-330 тыс. л.н. (MIS 11-10)). Наиболее выразительной частью раннепалеолитических коллекций являются крупные галечные и бифасиально обработанные орудия, включающие чопперы, пики, рубила, нуклевидные скребки и кливеровидные изделия. Среди орудий на сколах выделяются небольшие серии скребловидных, шиповидных и выемчатых изделий, которые приобретают определенные признаки стандартизации. В первичном расщеплении финальноашельской индустрии отмечаются элементы, характернье для леваллуазской технологии, такие как оформление у нуклеусов выпуклого фронта скальвания и специально подготовленной ударной площадки. В ичелом представленные комплексы, определенно, имеют ряд общчи черт, демонстрирующих большое сходство в приемах оформления и типах каменных изделий.

Ключевые слова: Дагестан, археологические стоянки, ашель, каменные индустрии, ранний палеолит.

\author{
A.G. Rybalko ${ }^{\bowtie}$, A.V. Kandyba \\ Institute of Archaeology and Ethnography SB RAS \\ Novosibirsk, Russia \\ E-mail:rybalko@archaeology.nsc.ru
}

\section{Research of the Darvagchai-Zaliv-4 Multi-Layer Site in 2021}

The article provides the latest results obtained during the research of the site Darvagchay-Zaliv-4 (Southeastern Dagestan). During the excavations, additional archaeological materials were found confirming the presence of three different-time complexes of artifacts at the site, the chronological framework of which was based on the results of malacofauna analysis, paleomagnetic studies and absolute OSL dating. The lithic industry of the first complex found in Layer 3 (pebble-gravel deposits) was attributed to the final Acheulean period. Eluvial-deluvial and proluvial processes were main in the deposition of sediments. Chronologically, the time of its existence was determined to the range of 250-220 ka BP (MIS 7). Artefacts of another stone collection found in Layer 5 (sea gravel and sand) belong to the late Acheulean and are the evidence of the earliest appearance of ancient man in the territory under consideration (380-330 ka BP (MIS 11-10)). The most expressive part of the early Paleolithic collections are large pebble and bifacially processed tools including choppers, spikes, cleavers, core scrapers, and cleaver-type articles. Among the tools on the flakes, there are small series of scraper-shaped, spike-shaped, and notched tools. The primary reduction of the final Acheulean industry includes a number of common features typical of the Levallois technique such as forming a convex shearing plane in a nucleus and a prepared striking platform. Generally, the provided complexes demonstrate a clear similarity in the design techniques and types of products.

Keywords: Dagestan, archeological sites, Acheulean, lithic industries, early Paleolithic. 
Стоянка Дарвагчай-Залив-4 обнаружена в 2010 г. сотрудниками ИАЭТ СО РАН в ходе обследования правого берега р. Дарвагчай (Дербентский р-н, Республика Дагестан). Памятник расположен на правом берегу Геджухского водохранилища в средней части высокого (около 20 м) крутого склона древнекаспийской террасы. Стационарные исследования стоянки, проводившиеся в течение последнего десятилетия, позволили установить точные хронологические позиции раннепалеолитических индустрий, получить подробные сведения о стратиграфии объекта, а также выразительный набор палеолитических изделий, наиболее характерной чертой, которого является наличие ашельских макроорудий [Рыбалко, 2014; Кандыба, Рыбалко, 2016].

В 2021 г. были сделаны две прирезки к основному раскопу в северо-восточном $(4 \times 2$ м) и юговосточном $(5 \times 2$ м) направлениях, общая раскопанная площадь составила $18 \mathrm{~m}^{2}$ (рис.1). Наиболее полно вскрытые отложения представлены на юговосточной стенке раскопа, всего выделено 8 геологических горизонтов (краткое описание дается сверху вниз).

Слой 1а. Гумусированный суглинок (современная почва). Мощность 0,15 м.

Слой 1б. Серо-коричневый опесчаненный суглинок. Генезис отложений субаэральный (элювиально-делювиальный). Мощность до 1 м.

Слой 1в. Буро-коричневый, тяжелый суглинок (палеопочва). Часть слоя (верхняя половина) разру- шена склоновыми процессами. Слой содержит среднепалеолитические артефакты. Мощность до 0,4 м

Слой 2. Коричневый местами сильно карбонизированный лессовидный суглинок. Генезис субаэральный. В верхней трети слоя (контактная зона) встречаются единичные среднепалеолитические артефакты. Мощность до 3,5 м.

Слой 3. Гравийно-галечные отложения различной степени окатанности. В заполнителе глинистый песок, суглинки. Генезис отложений сложный, ведущую роль играли пролювиально-делювиальные и аллювиальные (горный аллювий) процессы. Слой содержит раннепалеолитические артефакты. Мощность до 1,5 м.

Слой 4. Прибрежно-морские пески, светло-серые, косослоистые. Мощность до 0,45 м.

Слой 5. Гравийно-галечные отложения. В заполнителе светло-серый детритусовый песок с включением раковин морских моллюсков разной сохранности. Слой содержит палеолитические артефакты. Мощность до 0,45 м.

Слой 6. Тонко слойчатые серые пески с горизонтальными прослоями детритусового песчаника. Генезис отложений прибрежно-морской. Мощность до 1,5 м.

Обнаруженная в процессе раскопок сводная коллекция раннепалеолитических артефактов насчитывает 90 экз. каменных изделий.

Артефакты обнаруженные в пролювиальном, галечно-гравийном горизонте (слой 3 ) имеют разную степень сохранности поверхности. Большая часть

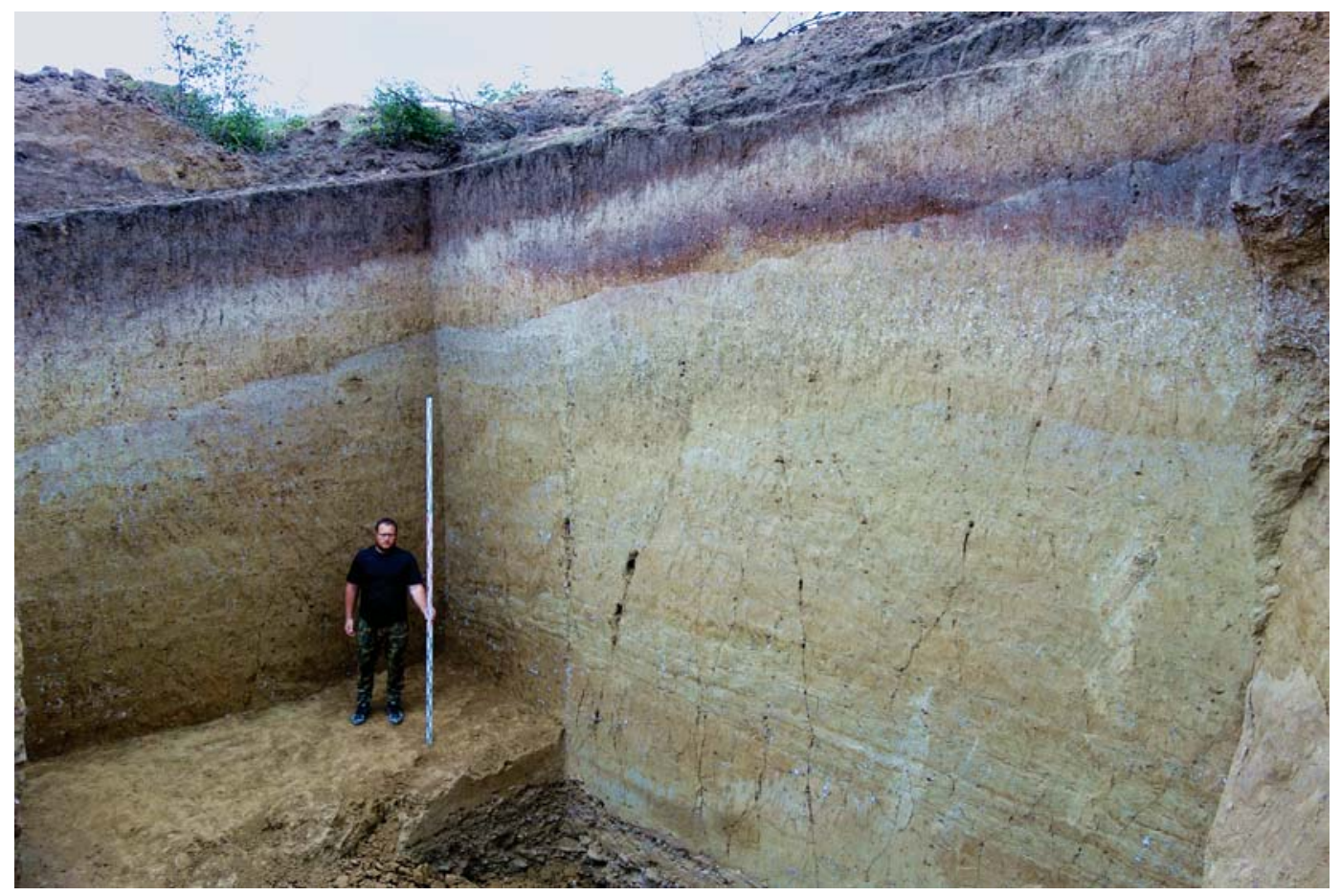

Puc.1. Стоянка Дарвагчай-Залив-4, общий вид раскопа 2021 г. 
изделий средне (25\%) и слабо (35\%) окатанные. Сильно окатанных артефактов $8 \%$, на оставшейся части (32\%) изделий полностью отсутствуют какие-либо следы сглаживающего воздействия. Характерных следов соударений в водной среде на поверхностях артефактов не наблюдается, это означает, что окатывание археологического материала происходило не в направленном водном потоке, а в среде, исключавшей резкие и сильные соударения. Вероятнее всего данный процесс происходил в водно-песчаной взвеси в приливно-отливной пляжной зоне. Именно этим можно объяснить разную степень сохранности поверхности артефактов и резкое увеличение не окатанных и слабо окатанных каменных изделий по мере удаления от края террасы. Условия залегания и состояние изделий из камня свидетельствуют о незначительной, частичной переотложенности комплекса.

Представленная индустрия является моно сырьевой, для изготовления каменных орудий использовались гальки и разной степени окатанные обломки преимущественно из кремня (90\%) и в значительно меньшей мере окремненного известняка (10\%). Данные горные породы в изобилии встречаются в естественных и искусственных обнажениях в центральной части склона и у основания древнекаспийской террасы, а также являются непосредственной составляющей культуросодержащего горизонта.

Археологическая коллекция из слоя 3 состоит их 74 артефактов. В ней представлены следующие категории каменных изделий: отбойник; нуклевидные формы - 4; отщепы - 38; обломки и осколки 27 ; чешуйки -4 .

Нуклевидные формы представлены типологически выраженными ядрищами (3) и нуклевидным обломком. Два ядрища одноплощадочные монофронтальные, относятся к простой плоскостной системе расщепления. В качестве заготовок использовались гальки. Первый нуклеус подтреугольной формы, площадка естественная, на фронте негатив снятия отщепа среднего размера. Другой прямоугольной формы, площадка подготовлена сколами, на фронте негативы удлиненных снятий (рис. 2, б). Последний нуклеус двухплощадочный монофронтальный встречного принципа скалывания. Площадки естественные, на фронте негативы снятий отщепов, часть из которых упирается в заломы.

Продукты первичного расщепления включают: сколы (38), преимущественно укороченные, крупного и среднего размера, с ярко выраженным ударным бугорком; обломки (27), объемные угловатые куски породы разных размеров и форм, и чешуйки (4).

Группа изделий со следами вторичной обработки насчитывает 19 предметов, кроме них в орудийный набор включены два леваллуазских отщепа и отбойник. Орудийный набор состоит из: рубила (рис. 2, 5), ножа, острия (рис. 2, 1), атипичного скребка, скребел (4), шиповидных (5) и выемчатых (3) (рис. 2,2$)$ изделий, отщепа и обломков $(2)$ с ретушью. В качестве заготовок использовались сколы (5), обломки (11) и гальки (3).

Леваллуазские сколы подтреугольной формы, площадки выпуклые двугранные (рис. 2, 3, 4). Отбойник представляет собой крупную овальную гальку, на обоих поперечных краях которой видны многочисленные следы забитостей.

Наиболее выразительным орудием является рубило с естественным обушком. В качестве исходной формы использовалась плоская крупная галька, одна сторона орудия по всей поверхности оформ-
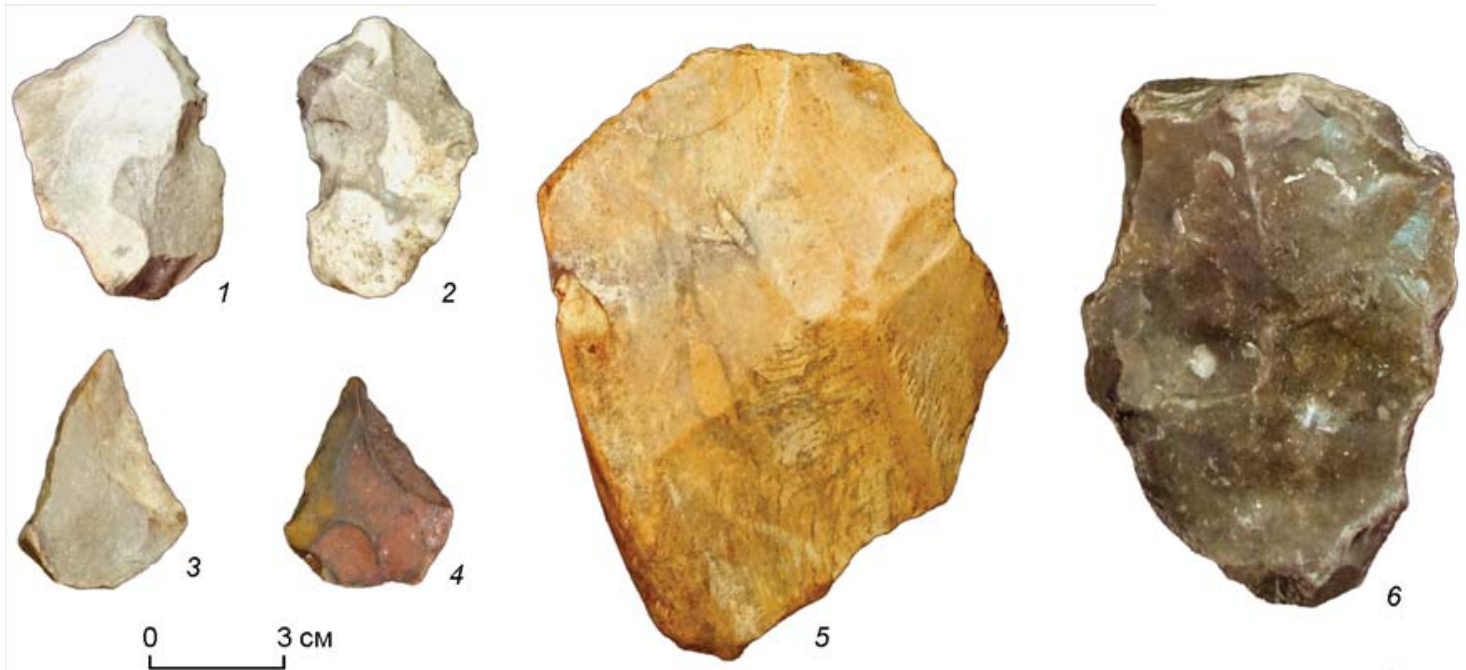

Puc. 2. Каменные артефакты стоянки Дарвагчай-Залив-4 (слой 3).

1 - острие; 2 - выемчатое орудие; 3, 4 - сколы леваллуа; 5 - рубило; 6 - нуклеус. 
лена центростремительными сколами, вторая частично покрыта галечной коркой, продольный край, противолежащий обушку, имеет дополнительную обработку сколами (рис. 2, 5).

Группа орудий на отщепах и обломках состоит из типологически выраженных скребел, шиповидных и выемчатых изделий, которые приобретают определенные признаки стандартизации, а также невыразительных отщепов и обломков с ретушью. Скребла представлены одинарными боковыми вариантами с прямыми и слабовыпуклыми лезвиями. В категории выемчатых орудий встречаются как клектонские разновидности анкошей, так и ретушное оформление. Шиповидные изделия подготавливались одной или двумя сопряженными выемками и ретушью. Отщепы и обломки с нерегулярной обработкой по одному краю, ретушь мелкая прерывистая.

Имеющиеся на настоящий момент данные позволяют определить памятник как стоянку-мастерскую. Комплексный анализ материалов дает возможность утверждать, что по своим техникотипологическим характеристикам они более всего соответствуют финальному ашелю. Данному определению не противоречат и хронологические рамки индустрии (250-220 тыс. л.н. (MIS 7)), установленные ранее на основании серии дат, полученных методом OSL. В целом представленная коллекция хорошо дополняет археологические материалы, полученные в ходе раскопок предыдущих лет, и дает возможность более обоснованно подтвердить выводы, сделанные ранее [Рыбалко, Кандыба, 2019].

Коллекция из слоя 5 состоит из 17 артефактов. Материалы нижнего галечника демонстрируют близкое состояние сохранности поверхности. Большинство изделий имеет слабую степень окатанности (50 \%) или сохраняет свежие грани (35\%). Если артефакты из слоя 3 в ряде случаев, помимо сглаженности граней, имеют следы забитостей, то на большинстве изделий данного комплекса подобных следов нет.

Нуклевидные изделия включают две гальки с единичными сколами (проба камня) и единственный нуклеус, выполненный на гальке из песчаника, который наглядно демонстрирует долечную технику скалывания (рис. 3, 4).

Основную часть продуктов первичного расщепления составляют сколы (8), преимущественно укороченные, средних и крупных размеров, а также обломки (5), в основном плоские, средних размеров.

Орудийный набор состоит из чоппера (рис. 3 5), пика (рис. 3,1$)$ шиповидных (2) изделий и обломка с ретушью (рис. 3,3 ). В качестве заготовок использовались сколы (2), гальки (2) и обломок.

Наиболее выразительными изделиями являются чоппер и пик. В качестве заготовки в первом

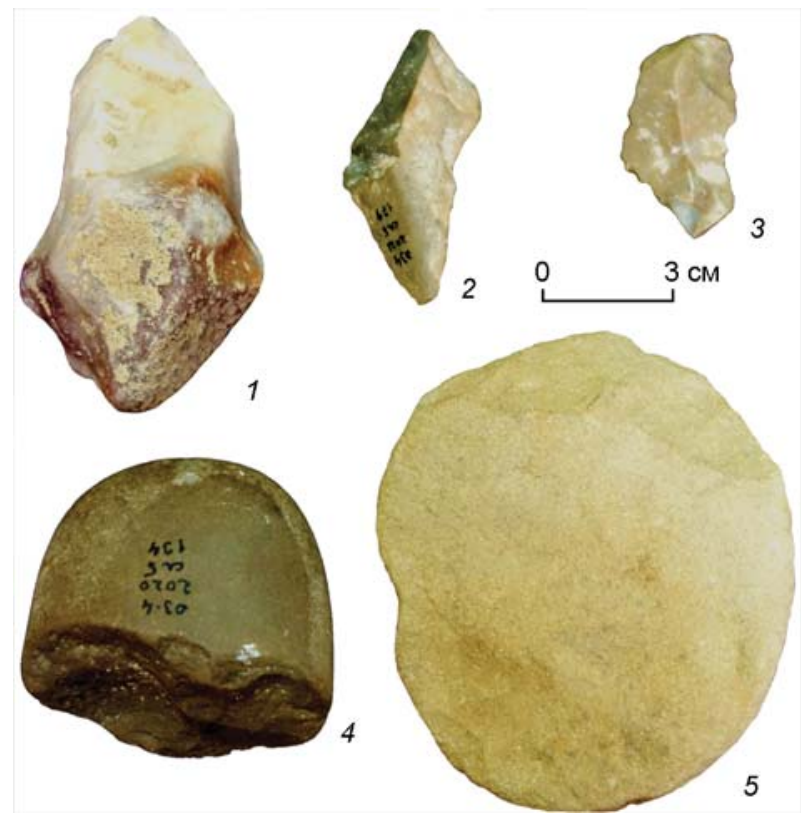

Puc. 3. Каменные артефакты стоянки Дарвагчай-Залив-4 (слой 5).

1 - пик; 2 - пластинчатый скол; 3 - обломок с ретушью; 4 - нуклеус; 5 - чоппер.

случае использовалась овальная плоская галька из песчаника, на поперечном крае которой оформлено выпуклое лезвие. Пик трехгранный, оформлен крупными и средними сколами, на острие видны забитости.

Основные приемы вторичной отделки, формы и типы орудий на сколах и обломках из слоя 5 не отличаются от тех, что были описаны выше для слоя 3.

Хронологические рамки культуросодержащего горизонта ранее основывались на палеонтологических данных (анализ малакофауны) и палеомагнитных исследованиях [Рыбалко, Янина, 2017]. В 2019 г. для слоя 4 и 5 стоянки Дарвагчай-Залив-4 методом OSL (оптически стимулируемое люминесцентное датирование) была получена серия из трех дат, на основании которых было установлено, что время формирования слоев 4 и 5 соответствует периоду 380-350 тыс. л.н. (MIS 11-10).

Общий анализ археологических материалов раннепалеолитических комплексов (слои 3 и 5) позволяет сделать следующие выводы о характере индустрий стоянки. Обнаруженные артефакты отличает разная степень сохранности поверхности, варьирующая от изделий с несглаженными «свежими» ребрами, до сильно «замытых» предметов. Анализ планиграфии, наряду с данными стратиграфии, показывает, что артефакты претерпели минимальные пространственные перемещения в постседиментационный период. Данные каменные индустрии сформировались на местной сырьевой базе. В качестве исходного сырья использовался 
кремень, окремненный известняк и песчаник в виде галек, обломков и желваков. Данные разновидности каменного сырья являются непосредственной составляющей культуросодержащих горизонтов стоянки и хорошо прослеживаются в нескольких обнажениях на близлежащей территории.

Набор орудийных типов и характер вторичной обработки практически не изменяется по культурно-литологическим подразделениям, наиболее выразительными изделиями являются макроорудия, представленные чоппером, пиком и рубилом. Основная причина существующих различий представленных коллекций заключается в их разной хронологической позиции. Однако, не смотря на существенный хронологический разрыв, коллекции артефактов демонстрируют глубокое сходство по основным технико-типологическим параметрам, анализ всех аспектов каменного инвентаря свидетельствует, что в период формирования слоев 3 и 5 на данной территории обитали носители одной индустриальной традиции, базировавшейся на местной полисырьевой базе.

На памятнике представлены все циклы обработки камня. Фиксирующиеся приемы первичного расщепления и вторичной обработки относятся к простейшим вариантам. Есть свидетельства использования примитивных техник дробления и долечной. Среди сколов преобладают массивные подпрямоугольные и широкие заготовки. Вторичная обработка в виде ретуши чаще всего была краевой и лишь в редких случаях изменяла морфологию заготовки. Среди выделенных категорий орудий преобладают скребла, шиповидные и выемчатые изделия. Наиболее выразительной частью орудийного набора являются ашельские макроорудия [Рыбалко, 2016]. Все вышеперечисленные данные позволяют определить памятник как многократно посещаемую, базовую стоянку-мастерскую, где осуществлялась деятельность, связанная с последовательным серийным изготовлением разнообразных орудий. Облик основных категорий типологически выраженных артефактов, а также возраст культуросодержащих отложений позволяют отнести данные комплексы к финальному и позднему ашелю.

\section{Благодарности}

Исследование выполнено при финансовой поддержке гранта РФФИ № 19-09-00006_а.

\section{Список литературы}

Кандыба А.В., Рыбалко А.Г. Ранний палеолит ЮгоВосточного Дагестана (по материалам памятника Дар- вагчай-залив-4) // Известия Алтайского гос. ун-та. Сер.: История, политология. - 2016. - № 2 (90). - С. 210-214.

Рыбалко А.Г., Кандыба А.В. Исследования среднего палеолита Западного Прикаспия // Гуманитарные науки в Сибири. - 2019. - Т. 26. - № 2. - С. 5-10.

Рыбалко А.Г. Ранний палеолит Западного Прикаспия (новые данные) // Труды IV (XX) Всероссийского археологического съезда. Т. І. - Казань, 2014. - С. 128-132.

Рыбалко А.Г. Бифасиально обработанные орудия Дарвагчайского геоархеологического района (Юго-Восточный Дагестан) // Проблемы археологии, этнографии, антропологии Сибири и сопредельных территорий Новосибирск: Изд-во ИАЭТ СО РАН, 2016. - Т. XXII. C. $152-155$.

Рыбалко А.Г., Янина Т.А. Обоснование возраста раннепалеолитической стоянки Дарвагчай-Залив-4 (Юго-Восточный Дагестан) // Проблемы археологии, этнографии, антропологии Сибири и сопредельных территорий - Новосибирск: Изд-во ИАЭТ СО РАН, 2017. T. XXIII . - C. 190-194.

\section{References}

Kandyba A.V., Rybalko A.G. The Study of Early Paleolithic of Dagestan: New Data (According to the Materials of the Site Darvagchai-Bay-4). In Izvestiya Altaiskogo gos. uni-ta. Seriya: Istoriya, politologiya. 2016, No 2 (90), pp. 210-214. URL: http://izvestiya.asu.ru/article/ view/\%282016\%294-41 (In Russ.).

Rybalko A.G., Kandyba A.V. Middle Palaeolithic Investigations in the Western Precaspian Region. Gumanitarnye nauki v Sibiri, 2019, vol. 26, No. 2, pp. 5-10. DOI: 10.15372/HSS20190201. (In Russ.).

Rybalko A.G. Rannij paleolit Zapadnogo Prikaspija (novye dannye). In Trudy IV (XX) Vserossijskogo arheologicheskogo sezda, vol. I. Kazan, 2014, pp. 128-132. (In Russ.).

Rybalko A.G. Bifacial Tools According to GeoArcheological Area Darvagchay (South-Eastern Dagestan). In Problems of Archaeology, Ethnography, Anthropology of Siberia and Neighboring Territories. Novosibirsk: IAET SB RAS Publ., 2016, vol. XXII, pp. 152-155. URL: https:// archaeology.nsc.ru/wp-content/uploads/2018/05/ses 2016 min.pdf. (In Russ.).

Rybalko A.G., Yanina T.A. Age of the Early Paleolithic Site of Darvagchay-Zaliv-4 (Southeastern Dagestan). In Problems of Archaeology, Ethnography, Anthropology of Siberia and Neighboring Territories. Novosibirsk: IAET SB RAS Publ., 2017., vol. XXIII, pp. 190-194. URL: https:// archaeology.nsc.ru/wp-content/uploads/2018/05/ses_2017. pdf. (In Russ.).

Кандыба А.B. https://orcid.org/0000-0003-0985-9121 Рыбалко А.Г. https://orcid.org/0000-0002-8749-0465 